\title{
Relação entre a desvalorização profissional e o mal-estar docente
}

\author{
Relación entre la desvalorización profesional y el malestar docente \\ Relation between professional devaluation and teacher malaise
}

\author{
Luana Maria Santos da Silva ${ }^{1}$ \\ Fabrine Diniz Pereira ${ }^{2}$ \\ Tanise Paula Novello ${ }^{3}$ \\ Daniel da Silva Silveira ${ }^{4}$
}

\begin{abstract}
Resumo
Pesquisas evidenciam que uma porcentagem significativa da população sofre de estresse laboral, neste contexto destaca-se os profissionais da área da educação, visto que, um número significativo de professores tem uma rotina corrida e excessiva demanda de trabalho. Somado a isso, o convívio com alunos, pais e colegas que, por vezes, é conflituoso, são estressores que tornam os docentes vulneráveis ao mal-estar. Neste trabalho, o mal-estar é entendido como a presença de obstáculos relacionados ao volume de trabalho e à precariedade das condições para lidar com as adversidades, assim como as altas demandas emocionais, que, por decorrência, refletem-se em condutas de insatisfação com a profissão, falta de comprometimento, absenteísmo, alto nível de estresse e anseio em desistir de lecionar. Desta forma, essa pesquisa tem como objetivo investigar como a desvalorização do professor pode ser um desencadeador do mal-estar nos docentes. Para tanto, realizou-se entrevistas com professores de matemática das cidades de Rio Grande - RS e São José do Norte - RS. O discurso dos professores evidencia que a maioria deles estão desmotivados com a carreira docente, principalmente pela desvalorização da profissão. Ademais, é apontado nessa investigação que os aspectos salariais e carga horária estão entre os principais fatores que podem desencadear o mal-estar docente.
\end{abstract}

Palavras-Chave: Desvalorização Profissional; Discurso; Mal-estar; Professores.

\section{Resumen}

Las investigaciones evidencian que un porcentaje significativo de la población sufre de estrés laboral, en este contexto se destaca a los profesionales del área de la educación, ya que un número significativo de profesores tiene una rutina de carrera y excesiva demanda de trabajo. Al sumado a ello, la convivencia con alumnos, padres y colegas que, a veces, es conflictiva, son estresores que hacen a los docentes vulnerables al malestar. En este trabajo, el malestar se entiende como la presencia de obstáculos relacionados con el volumen de trabajo y la precariedad de las condiciones para lidiar con las adversidades, así como las altas demandas emocionales, que, por consecuencia, se reflejan en conductas de insatisfacción con la profesión, falta de compromiso, absentismo, alto nivel de estrés y anhelo en desistir de enseñar. De esta forma, esta investigación tiene como objetivo investigar cómo la desvalorización del profesor puede ser un desencadenante del malestar en los docentes. Para ello, se realizaron entrevistas con profesores de matemáticas de las ciudades de Rio Grande - RS y São José do Norte - RS. El discurso de los profesores evidencia que la mayoría de ellos están desmotivados con la carrera docente, principalmente por la devaluación de la profesión. Además, es señalado en esa investigación que los aspectos salariales y carga horaria están entre los principales factores que pueden

\footnotetext{
${ }^{1}$ Mestranda do Programa de Pós-Graduação em Educação em Ciências; Universidade Federal do Rio Grande FURG; Rio Grande, Rio Grande do Sul, Brasil; luanamaria@ furg.br.

${ }^{2}$ Licencianda em Matemática; Universidade Federal do Rio Grande - FURG; Rio Grande, Rio Grande do Sul, Brasil; fabrinediniz@hotmail.com.

${ }^{3}$ Doutora em Educação Ambiental; Universidade Federal do Rio Grande - FURG; Rio Grande, Rio Grande do Sul, Brasil; tanisenovello@ furg.br.

${ }^{4}$ Doutor em Educação em Ciências; Universidade Federal do Rio Grande - FURG; Rio Grande, Rio Grande do Sul, Brasil; dssilveira@furg.br.
} 


\begin{abstract}
Researches show that a significant percentage of the population suffers from occupational stress, in this context the professionals in the area of education stand out, since a significant number of teachers have an intense routine and excessive demand for work. Added to this, the daily contact with students, parents and colleagues that is sometimes conflicting, are stressors that make teachers vulnerable to malaise. In this study, malaise is understood as the presence of obstacles related to the volume of work and the precariousness of the conditions to deal with adversities, as well as the high emotional demands, which, as a consequence, reflect in behaviors of dissatisfaction with the lack of commitment, absenteeism, a high level of stress and a desire to give up teaching.Thus, this research aims to investigate how the devaluation of the teacher can be a trigger for malaise in teachers. Withal, interviews were conducted with mathematics teachers from the cities of Rio Grande - RS and São José do Norte - RS. The teachers' discourse shows that most of them are unmotivated with their teaching career, mainly due to the devaluation of the profession. Furthermore, it is pointed out in this investigation that wage and workload aspects are among the main factors that can lead to teacher malaise.
\end{abstract}

Keywords: Professional Devaluation; Speech; Malaise; Teachers

\title{
1. Introdução
}

Atualmente, a sala de aula não é vista como um espaço atrativo, pelo contrário, ela se tornou um espaço que não instiga interesse e é distante da realidade social de muitos alunos, o que pode afetar a relação entre professor e aluno e como consequência o processo de ensino e de aprendizagem. Logo, cria-se um ambiente em que o convívio se torna pouco flexível, e o professor acaba tendo mais predisposição para desenvolver um mal-estar.

O mal-estar docente é um fenômeno cada vez mais presente na sociedade e é ocasionado por diferentes fatores de estresse, tanto externos como internos à pessoa. Adota-se a definição de mal-estar a partir dos estudos de Esteve (1992, p. 31) que caracteriza o malestar como sendo "os efeitos negativos permanentes que afetam a personalidade do professor em resultado das condições psicológicas e sociais em que exerce a docência". Em concordância, Gonçalves et al. (2008, p. 4598) conceitua o mal-estar como sendo os “comportamentos que expressam insatisfação profissional, elevado nível de estresse, absentismo, falta de empenho em relação à profissão, desejo de abandonar a carreira profissional, podendo, em algumas situações, resultar em estados de depressão".

Já por sua vez, Jesus (2002) defende que o mal-estar é um fenômeno social emergente da atualidade, pois notou-se um aumento no número de professores com sintomas de malestar nos últimos tempos, um dos motivos pode estar relacionado a que em tempos passados o professor não desenvolvia índices maiores de insatisfação, estresse ou exaustão do que outros profissionais. Desta forma "o mal-estar docente é um fenômeno da sociedade atual, estando interligado com as mudanças sociais que ocorreram nas últimas décadas, com implicações no comportamento dos alunos na escola[...]" (JESUS, 2002, p. 15). 
Deste modo, o objetivo desta pesquisa foi investigar como a desvalorização do professor pode ser um desencadeador do mal-estar nos docentes. Para isso, optou-se por realizar uma entrevista semiestruturada com professores de matemática de escolas públicas dos Anos Finais do Ensino Fundamental e do Ensino Médio da cidade de Rio Grande - RS e de São José do Norte - RS.

\section{Operar Metodológico}

Para a realização deste estudo, optou-se por usar a técnica de entrevistas, pois através dela o pesquisador consegue obter uma quantidade maior de informações para a escrita de um trabalho com qualidade (BRITTO JÚNIOR; FERES JÚNIOR, 2011). A entrevista foi realizada com quatro professores de matemática dos Anos Finais do Ensino Fundamental e do Ensino Médio das cidades de São José do Norte - RS e Rio Grande - RS. Os professores foram escolhidos pela proximidade com os autores deste trabalho e o único critério aplicado foi a diferença do tempo de docência. A entrevista foi organizada por meio de um roteiro semiestruturado e com o auxílio de um gravador, para facilitar o registro. O roteiro da entrevista (Figura 1) foi composto por 20 questões.

\begin{tabular}{l}
\multicolumn{1}{c}{ Figura $1-$ Roteiro da entrevista realizada com os professores. } \\
\hline Roteiro da Entrevista \\
\hline Idade \\
Sexo \\
Ano de formação \\
Tempo de atuação na rede pública \\
Atua em que tipo de escola? \\
Qual sua formação (Graduação e Pós-Graduação)? \\
Como é sua relação com os alunos em sala de aula? \\
O que você sente/sentimentos ao ministrar suas aulas? \\
Como são seus momentos de planejamento das aulas? \\
Você se sente realizado como profissional? Por quê? \\
\hline Quais são os aspectos positivos de ser professor e quais são os aspectos negativos? \\
Você já teve algum sintoma de adoecimento psicológico que possa ser relacionado ao trabalho? Qual? \\
\hline Faz uso de algum medicamento psicoativo? Se sim, qual? \\
\hline Faz ou já fez algum tipo de acompanhamento psicológico? Se sim, qual? \\
\hline Você percebe sintomas de estresse nos seus colegas? De que forma isso se manifesta? \\
\hline Como você percebe a importância social do professor? \\
\hline O que você gostaria que mudasse na sua profissão? \\
\hline Hoje há baixa procura pelas licenciaturas, a que você atribui tal fato? \\
\hline O que vocè considera condições ideias de trabalho? \\
Às vezes você pensa em trocar de profissão? Se sim, quais os motivos que levam a ter essa vontade e quais te fazem \\
permanecer nela? \\
\hline
\end{tabular}

Fonte: Os autores.

Como fica evidente através da figura 1, o roteiro aborda diferentes assuntos, dentre eles, variáveis demográficas e laborais, condições de trabalho, sentimentos em relação a 
alunos e planejamento das aulas, importância social do professor e grau de satisfação profissional. Após a etapa das entrevistas realizou-se a transcrição dos relatos para posteriormente analisar as falas dos professores.

A partir da análise das variáveis demográficas e laborais, caracterizou-se os entrevistados, evidenciando a formação, o tempo de atuação na docência, o tipo de escola em que trabalha, a idade e o sexo. Cabe salientar que todos os entrevistados têm formação inicial em Licenciatura em Matemática e a concluíram entre os anos de 1993 e 2005. Dos entrevistados, $75 \%$ possuem pós-graduação e essa constatação é corroborada com os dados do Instituto Nacional de Estudos e Pesquisas Educacionais Anísio Teixeira (INEP, 1999) que apontam um aumento no número de professores que possuem pós-graduação.

Outro registro para traçar o perfil dos entrevistados é em relação a faixa etária dos entrevistados, a média de idade dos professores é de 40 anos. Sendo que $75 \%$ dos entrevistados são do gênero feminino. Cabe ressaltar que $50 \%$ dos professores atuam tanto em escolas de Ensino Fundamental quanto de Ensino Médio, 25\% somente em escolas da primeira etapa de escolarização e $25 \%$ somente em escolas da segunda etapa. O tempo de experiência na docência em escolas públicas é mostrado na figura abaixo (Figura 2), sendo possível observar que o maior número de professores com experiência na docência está no intervalo de seis a 10 anos.

Figura 2 - Tempo de atuação na rede pública dos entrevistados.

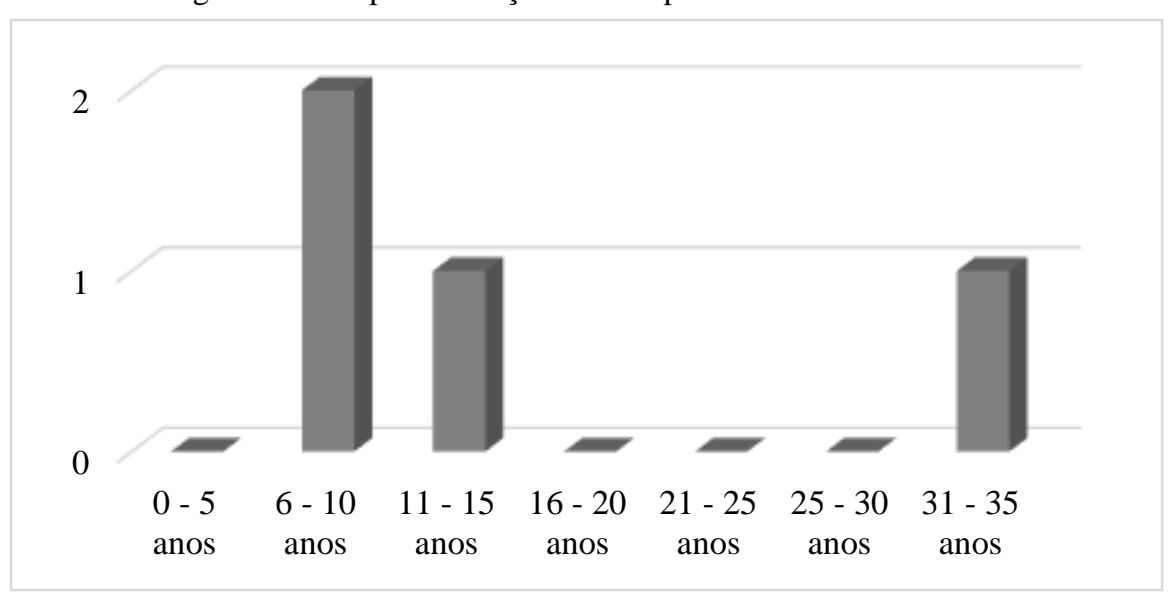

Fonte: Os Autores

Os discursos suscitados na entrevista serão expostos abaixo, bem como a corroboração de autores que contribuíram para o entendimento do assunto, que envolve sentimentos, anseios e angústias relacionados à prática docente. 


\section{Análise dos discursos dos professores}

A discussão desta seção baliza-se na análise dos registros que emergiram durante a conversa com os professores entrevistados. Serão apresentados extratos dos discursos dos professores para dar visibilidade ao que se está discutindo, articulando com autores que subsidiam a compreensão do fenômeno investigado. Os entrevistados serão identificados por Professor $\alpha$, Professor $\beta$, Professor $\gamma$ e Professor $\delta$, a fim de garantir o anonimato destes.

Ao analisar os discursos dos entrevistados notou-se que todas as respostas tinham em sua essência a insatisfação com a desvalorização da profissão docente. A falta de valorização do professor é evidente no Brasil, pois segundo informações divulgadas pela Fundação Educacional Varkey Gems, entre 21 países, o Brasil está em penúltimo lugar no critério de valorização de professores, embasados no salário, no respeito ao professor pelos alunos e no interesse pela profissão (IDOETA, 2013).

Foi possível observar, por meio dos discursos, que a relação dos professores com os alunos, na maior parte das vezes, é tranquila e pautada no respeito mútuo, como é evidenciado na fala do Professor $\beta$ : “quando estou no espaço da sala de aula os meus sentimentos são sempre bons e procuro manter uma troca de energias agradável com meus alunos". Freschi e Freschi (2013) afirmam que quando há uma relação de respeito entre o professor e o aluno isso torna o ambiente da sala de aula mais motivador e faz com que os alunos tenham maior interesse em frequentar a escola. Porém, do mesmo modo que todas as relações interpessoais, há momentos em que ocorre conflitos, e eles podem ter como origem diversos fatores, dentre eles, o desinteresse nas aulas por parte dos alunos, o excessivo número de alunos por sala de aula, o alto nível de reprovação na disciplina e até a própria estrutura das escolas. Esses fatores podem de certa forma, influenciar na saúde física e psicológica do professor, pois são empecilhos para a realização de um bom trabalho.

A desvalorização docente, de acordo com os professores, é mais acentuada em relação a remuneração salarial, carga horária de trabalho e as condições de trabalho oferecidas nas escolas. O Professor $\gamma$ afirma que "O professor atuando no Ensino Básico é pouco valorizado e por consequência para conseguir uma melhor remuneração precisa trabalhar em vários lugares, ficando sobrecarregado e muitas vezes sem condições de realizar o trabalho que desejaria fazer". Corroborando com esse discurso temos o estudo de Viera et al. (2010) que afirma que em decorrência da desvalorização salarial, os professores aumentaram sua jornada de trabalho em sala de aula, com o objetivo de melhorar a renda familiar, de modo que tenham melhores condições de vida. Porém esse aumento acarreta em uma sobrecarga, seja 
pelo tempo em sala de aula ou mesmo pela quantidade de serviço, contribuindo para que haja um crescente adoecimento dos professores.

Devido ao fato dos professores tentarem melhorarem a renda familiar, muitos professores estendem sua jornada de trabalho até 60 horas semanais. Porém, além da jornada em sala de aula, os professores ainda têm que separar tempo para o planejamento de suas práticas pedagógicas e para realizar as correções das atividades aplicadas em sala de aula, como provas e trabalhos. Além disso, as condições de trabalho de muitas escolas deixam a desejar, pois não proporcionam o material necessário para as atividades docentes, inibindo iniciativas de professores criativos que demandem recursos financeiros (LIPP, 2012).

Esses fatores, contribuem para que os professores não se sintam realizados na profissão docente, argumento evidenciado na fala do Professor $\gamma$, “Apenas não sou realizada com minha carreira profissional porque gostaria de ser mais valorizada e ter uma carreira que me propiciasse uma ascensão profissional, o que no presente não acontece no sistema público estadual”. A partir desse fato, temos o estudo de Lipp (2012), que afirma que:

ocorreu uma deterioração das condições da formação e da prática profissional do professorado no Brasil, hoje tão desvalorizado no próprio universo acadêmico, na mídia e na sociedade em geral. Diversos trabalhos na literatura mundial mostram que ser professor é uma das profissões mais estressantes na atualidade. (p. 15)

Com essa deterioração a busca por graduações em licenciatura caiu, pois segundo o estudo de Justino (2015) apesar da ampliação do número de vagas na Educação Superior, há queda na procura por cursos de licenciatura e, muitos dos que concluem não tem como meta atuar na sala de aula. Além disso, constatou-se que, as licenciaturas, muitas vezes servem como porta de entrada na universidade para quem deseja, eventualmente, pedir transferência para outro curso. Esses números podem ser percebidos desde a quantidade de matrículas e concluintes até as altas taxas de evasão na Educação Superior, tanto público quanto privado. Outra pesquisa relata que somente $5 \%$ dos melhores estudantes que se formam no Ensino Médio desejam seguir a carreira docente (TAKAHASHI, 2008).

Todos esses fatores geram sentimentos de mal-estar nos professores, com isso muitos ficam irritadiços, sem paciência com alunos, usam um grande número de atestados e não tem prazer em lecionar. Embora todos os entrevistados tenham relatado que não sentem sintomas de mal-estar, como é possível observar no relato do Professor $\gamma$, "Aprendi com a experiência, que aquilo que nos incomoda precisa ser resolvido, ou modificado. Também penso que o trabalho é uma parte apenas da minha vida", eles percebem esses sintomas de mal-estar 
nitidamente em muitos colegas, assim como fica explícito na fala da Professor $\delta$ "Percebo bastante estresse nos meus colegas, eles ficam com atitudes grosseiras com os alunos, ficam reclamando dos colegas e dos alunos, além disso não tem vontade de lecionar. Alguns chegam ao ponto de quase não suportarem ficar dentro da sala de aula. Suportam porque é o ganha pão”.

Um estudo realizado por Farias (2013) mostra que cerca de $20 \%$ dos professores pedem afastamento por licença médica, e cada licença, o educador fica em média três meses fora da sala de aula, e segundo pesquisa da Revista da Confederação Nacional dos Trabalhadores da Educação (CNTE) de 2012, as principais causas de afastamento de docentes da Educação Básica no Brasil são: "processos inflamatórios das vias respiratórias (17,14\%), depressão, ansiedade, nervosismo, síndrome do pânico (14,3\%) e estresse (11,7\%)" (TOKARNIA, 2015). Esses resultados são atribuídos a uma categoria que sofre de estresse em virtude das turmas numerosas, salários baixos e difíceis condições de trabalho. $\mathrm{O}$ estudo evidencia, ainda, que quando essas doenças não são tratadas nas causas, elas podem desencadear outras doenças.

Neste aspecto é importante salientar, que para um professor ser curado de doença psíquica, é necessário dedicar um tempo ao tratamento com acompanhamento psicológico e em alguns casos, fazer uso de medicações, até estar totalmente recuperado. O problema é que nem sempre a escola tem estrutura para dar continuidade ao trabalho do professor, pois muitas vezes os alunos ficam desassistidos até acabar a licença saúde do professor e ao voltar a lecionar, esse encontra outros desafios, devido a demanda de conteúdo acumulado. Essa situação pode gerar conflitos internos no professor e criar um ciclo de estresse permanente.

Pomiecinski e Pomiecinski (2014) afirmam que em decorrência do intenso estresse laboral que os professores sofrem, eles além de estarem vulneráveis a possibilidade de desenvolvimento do fenômeno do mal-estar, também estão suscetíveis a Síndrome de Burnout. Em concordância Lipp (2012), afirma que a profissão docente está entre as mais predispostas a desenvolver essa síndrome, pois esta se desenvolve em profissões que mantem contato interpessoal intenso e promovem um vínculo que auxilia o desenvolvimento do outro.

Burnout tem como tradução literal a expressão "consumir em chamas" (LIPP, 2012), ainda de acordo com a referida autora a Síndrome de Burnout é entendida como sendo um "tipo especial de estresse ocupacional, caracterizado por profundo sentimento de frustação e exaustão em relação ao trabalho desempenhado, sentimento que aos poucos pode estender-se a todas as áreas da vida de uma pessoa” (LIPP, 2012, p. 64), ainda de acordo com Lipp 
Burnout é uma erosão gradual, e frequentemente imperceptível no início, de energia e disposição, como consequência de um stress crônico e prolongado, ou melhor, de uma incapacidade crônica para controlar o stress. Não acontece como resultado de eventos traumáticos isolados. O Burnout não ocorre de repente; é um processo cumulativo, começando com pequenos sinais de alerta, que, quando não são percebidos, podem levar o professor a uma sensação de quase terror diante da ideia de ter que ir à escola (LIPP, 2012, p. 65).

Com isso, é possível perceber que aos primeiros sintomas de estresse, ele deve ser tratado, pois muitos professores "deixam a profissão porque não conseguem lidar com os fatores estressantes; outros permanecem, mas parecem contar os dias que faltam para os fins de semana, para as férias e, finalmente, para a aposentadoria" (LIPP, 2012, p. 66). Com professores doentes e insatisfeitos é provável que a qualidade da educação não melhore, pois se os professores não receberem ajuda imediata, possivelmente, eles estarão lecionando desmotivados.

\section{Conclusão}

Pode-se perceber com este trabalho que são muitos os fatores que causam sobrecarga nos professores e deixam a rotina pesada e estressante. Situação que é agravada pela remuneração não compatível com a formação que ele possui. Nesse sentido, o professor tende a agregar mais carga horária, para tentar ter um salário adequado à sua formação, atuação e carga horária de trabalho. Esses aspectos mostram como o professor é desvalorizado e como isso influi na sua saúde física e emocional.

Com essa deterioração no contexto educacional fica evidente que a imagem do professor não é respeitada e valorizada como em tempos passados. A figura do professor, hoje, tem outras configurações, o qual o professor é visto, muitas vezes, como um profissional sem importância e valor social.

Embora o número de sujeitos desta investigação seja relativamente pequeno, pode-se afirmar pela busca de outras pesquisas, que as análises são fidedignas à realidade das escolas públicas. Não há uma única solução para minimizar os efeitos do mal-estar docente, mas através do que foi exposto neste trabalho, acredita-se que, dentre diversas possibilidades, uma estratégia para mudar este quadro de estresse na docência, seja promover formações continuadas, no período em que os professores estão na escola.

Ademais, nessas formações são necessários a abordagem de diversos temas, entre eles, motivação e estratégias de enfrentamento para lidar com o estresse, tanto individual quanto coletivamente. Outra possibilidade seria inserir profissionais da saúde nas escolas, para que os professores pudessem ter acesso a acompanhamento psicológico, tanto para tratar os 
transtornos relacionados ao mal-estar docente, quanto para adotar medidas que evitem o agravamento do mesmo.

\section{Referências}

BRITTO JÚNIOR, A. F; FERES JÚNIOR, N. A utilização da técnica da entrevista em trabalhos científicos. Evidência, Araxá, v. 7, n. 7, p.237-250. 2011. Disponível em: http://files.met2entrevista.webnode.pt/200000032-64776656e5/200-752-1-PB.pdf. Acesso em: 21 jul. 2017.

ESTEVE, J. M. O Mal-estar docente. Lisboa: Escher, 1992.

FARIAS, M. Cresce número de professores afastados por problemas psicológicos.

Globo.com: G1. Alagoas. 20 jan. 2013. Disponível em:

http://g1.globo.com/al/alagoas/noticia/2013/01/cresce-numero-de-professores-afastados-porproblemas-psicologicos.html. Acesso em: 03 jul. 2017.

FRESCHI, E. M.; FRESCHI, M. Relações interpessoais: a construção do espaço artesanal no ambiente escolar. Revista de Educação do Ideau, v. 8, n. 18, jul-dez. 2013. Semestral. Disponível em: http://www.ideau.com.br/getulio/restrito/upload/revistasartigos/20_1.pdf. Acesso em: 28 abr. 2017.

GONÇALVES, J. P. O mal-estar docente segundo a percepção de coordenadores pedagógicos da rede pública de cascavel. In: VIII CONGRESSO NACIONAL DE EDUCAÇÃO, 2008. Anais. 2008. p. 4596 - 4606. Disponível em: http://www.pucpr.br/eventos/educere/educere2008/anais/pdf/830_607.pdf. Acesso em: 13 mar. 2017.

IDOETA, P. A. Como valorizar a carreira de professor no Brasil? BBC Brasil. São Paulo. 15 out. 2013. Disponível em:

http://www.bbc.com/portuguese/noticias/2013/10/131015_valorizacao_professores_pai. Acesso em: 03 jul. 2017.

INSTITUTO NACIONAL DE ESTUDOS E PESQUISAS EDUCACIONAIS ANÍSIO TEIXEIRA (BR). Aumenta o número de professores com mestrado e doutorado. Brasília: Ministério da Educação e Cultura, 1999.

JESUS, S. N. Perspectivas para o bem-estar docente: Uma lição de síntese. Lisboa, Portugal: Centro de Recursos de Informação e Apoio Pedagógico. 2002

JUSTINO, G. Cursos de licenciatura enfrentam queda na procura em todo o Brasil. GaúchaZH. 02 jul. 2015. Disponível em: https://gauchazh.clicrbs.com.br/educacao-eemprego/noticia/2015/07/cursos-de-licenciatura-enfrentam-queda-na-procura-em-todo-obrasil-4793025.html. Acesso em: 03 jul. 2017.

LIPP, M. N. O estresse do professor.7ª ed. Campinas, SP: Papirus, 2012.

POMIECINSKI, J. A. S.; POMIECINSKI, C. M. Gestão escolar: uma reflexão sobre a saúde emocional do professor - entre o stress e a síndrome de burnout. In: Colóquio Internacional 
de Educação, 2014, Joaçaba: Universidade do Oeste de Santa Catarina, Disponível em: https://editora.unoesc.edu.br/index.php/coloquiointernacional/article/download/5188/3160. Acesso em: 30 nov. 2017.

TAKAHASHI, F. Carreira de professor atrai menos preparados. Folha de S. Paulo. São Paulo.09 jun. 2008. Disponível em:

http://www1.folha.uol.com.br/fsp/cotidian/ff0906200801.htm. Acesso em: 03 jul. 2017.

TOKARNIA, M. Problemas de saúde ainda afastam professores de sala de aula. 2015. Disponível em: http://www.ebc.com.br/educacao/2015/10/saude-do-professor-esta-ligadaboas-condicoes-de-trabalho-diz-cnte. Acesso em: 03 jul. 2017.

VIEIRA, J. S. et al. Constituição das doenças da docência. Cadernos da Educação, Pelotas, p.303-324, set./dez. 2010. Disponível em:

https://periodicos.ufpel.edu.br/ojs2/index.php/caduc/article/viewFile/1589/1475. Acesso em: 30 nov. 2017. 